\title{
Development of the UK Engagement Survey
}

Dr Camille B. Kandiko Howson, King's College London*

4.22 Waterloo Bridge Wing

King's College London

London SE1 9NH UK

camille.kandiko howson@kcl.ac.uk

$+44(0) 2078483838$

*corresponding author and location of research

Camille is a Senior Lecturer and Academic Head of Student Engagement at King's College London. Her current research focuses on international and comparative higher education, with areas of interest in student outcomes and learning gain, student engagement and the curriculum; interdisciplinarity and creativity; academic motivation, prestige and gender; and developing the use of concept mapping in higher education and intersectionality in research design.

Dr Alex Buckley, University of Strathclyde

16 Richmond Street

Glasgow G1 1XQ Scotland

alex.buckley@strath.ac.uk

+44 (0)1415483673

Alex is a Learning Enhancement Advisor at the University of Strathclyde. Before arriving at Strathclyde in 2015 he was Surveys Manager at the Higher Education Academy, where he developed the UK Engagement Survey. His research interests include the conceptual and political aspects of student engagement, and the use of student feedback for the enhancement of learning and teaching. 


\title{
Development of the UK Engagement Survey
}

\author{
Abstract \\ Student engagement has become a key feature of UK higher education, but until recently there has \\ been a lack of data to track, benchmark and drive enhancement. In 2015 the first full administration ran \\ in the UK of a range of survey items drawn from the US-based National Survey of Student Engagement \\ (NSSE). This is the latest example of international adaptations of NSSE, and was prompted by the need \\ to collect actionable data, related to core elements of learning and teaching, that can be used for \\ institutional improvement efforts. This paper describes the background and development of the UK \\ Engagement Survey (UKES) focusing on the two pilot years in 2013 and 2014 and the full administration \\ phase in 2015. This involved a complementary mix of qualitative and quantitative data analysis and \\ engagement with students in the testing process. Cognitive testing was conducted with 85 students over \\ two years and data from the full 2015 administration involved 24,387 students. The political context of \\ student engagement in relation to national satisfaction surveys and the implications of running a \\ generalist-based survey in a subject-specific higher education context are discussed.
}

Keywords: student engagement; student surveys; cognitive testing; survey design

Words: 7148 


\section{Introduction}

The student experience has come to the fore in UK higher education over the past decade. The Browne Review (2010), Higher Education White Paper in 2011 (Department for Business, Innovation \& Skills [BIS] 2011) and subsequent rise in tuition fees have put 'students at the heart of the system'. With the raised importance of the student voice, debate flourishes about 'students as consumers' and 'students as learners' and their position in relation to higher education and academic staff. Supported by the development of metrics, particularly the government-sponsored National Student Survey (NSS) launched in 2005, student satisfaction dominates the policy sphere through league tables and key performance indicators. This has led to a boom in student services and buildings, facilities and environments to support students.

At the same time, seminal work has stressed the important links between educational gain and the pedagogical practices undertaken within institutions (Gibbs 2010, 2012). In the UK, there has been increasing interest in evaluating and improving the amount, type and quality of effort that students invest in their studies. In particular, there has been growing interest in the National Survey of Student Engagement (NSSE), a survey which was developed in the US and which has now been adapted and used around the world (Coates \& McCormick 2014). The high-stakes nature of student survey data has led to competing discourses.

Partially to challenge the dominance of the NSS and also to develop data to support institutions to enhance the student learning experience, a group of institutions began exploring the use of engagement surveys in the UK. This led to a Higher Education Academy (HEA)-funded two-year pilot project exploring the viability of using items derived from the National Survey of Student Engagement (NSSE) in the UK, as well as piloting new UK-specific items. 


\section{Background and context}

The role of the National Student Survey (NSS)

A political driver of institutions' orientation towards students has been the development of the government-sponsored National Student Survey (NSS). The NSS originated in work on the Course Experience Questionnaire undertaken in Australia (Ramsden 1991), and was launched in the UK in 2005 as part of the quality assurance framework, and is now a very influential driver for universities. Data from the NSS is made public and universities' performance in most media league tables is heavily influenced by NSS results. The NSS covers particular aspects of support for teaching and learning and focuses on student satisfaction.

There are inevitably disadvantages in any methodology, and there is now an extensive literature critiquing NSS and other similar approaches (Wiers-Jenssen et al. 2002; Harvey 2003; Hanbury 2007; Williams and Cappuccini-Ansfield 2007); and moreover the NSS has faced strong opposition by several Students' Unions from the Russell Group, a network of research-intensive universities in the UK. Some have argued that the consumer theory basis of satisfaction surveys places the student in the role of customer and that the responsibilities and contribution of the student-as-learner are not represented. It has also been argued that it does not help institutions improve teaching provision (Harvey 2003). The unit of analysis as 'the course' silences arguments about institutional responsibility and the policy context (Sabri, 2011). Furthermore, whilst the breadth of the NSS allows for comparisons across institutions, it provides little detail for institutions to improve internally. The NSS does not at present touch on active student engagement, although there are proposals to do so in future (HEFCE 2015); it collects student perception data based on satisfaction measures. Within the survey, only nine questions 
relate broadly to learning. This highlights an implicit measure of students as consumers of education, with an inherent focus on 'satisfaction' as opposed to 'engagement' (Kuh 2009).

The development of the National Survey of Student Engagement (NSSE)

NSSE aims to evaluate student engagement with activities likely to enhance their learning outcomes (Kuh 2001a). It was established in 2000 in North America and has grown to the point that 315,815 students completed NSSE in 2015. NSSE was substantially derived from an earlier survey, the College Student Experiences Questionnaire (Pace 1984), and was based on a range of research demonstrating the impact of student effort on learning outcomes including:

- The importance of the amount of physical and psychological energy that the student devotes to the academic experience (Astin 1984)

- The diverse body of research distilled in the seven principles for good practice in undergraduate education (Chickering and Gamson 1987)

- The importance of deep learning (Marton and Säljö 1976; Entwistle et al 1979)

- The impact of the quality of effort (Pace 1982)

Pascarella and Terenzini (2005) summarise this research as follows: "[l]f, as it appears, individual effort or engagement is the critical determinant in the impact of college, then it is important to focus on the ways in which an institution can shape its academic, interpersonal, and extracurricular offerings to encourage student engagement" (p.602).

NSSE was developed by the Centre for Postsecondary Research at Indiana University, supported by the Pew Charitable Trusts. It was piloted in 1999, and since then over 1600 institutions in the US and Canada have used the survey. It was modified in 2013, with new item additions reflecting new areas of interest 
such as quantitative reasoning (McCormick et al 2013a). While the original motivation of the survey was to counterbalance the effect of simplistic league tables by providing information about good educational practices (Kuh 2001b), its design and administration is focused on helping institutions to enhance student learning.

The first substantial implementation of NSSE outside North America came in 2007, when the survey was adapted for Australia and New Zealand, with the development of the Australasian Survey of Student Engagement [AUSSE] (Coates 2010). NSSE has since been adopted in many different international contexts, including South Africa, China and Ireland (Coates \& McCormick 2014). Items from NSSE have been validated and cognitively tested in the US (Kuh 2001a; Ouimet et al 2001) and other countries, but not extensively in a UK context. The UK differs substantially from the US in offering largely subjectspecific degrees, without broad general education requirements. The effects of this difference have yet to be widely explored in testing student engagement survey items.

Context of student engagement in the UK

Somewhat confusingly, rather than being a new topic in UK higher education, student engagement has a long history but with a different focus. Going back to the Students' Union movements in the 1970s, there has been a collective and representational focus to student engagement in the UK (Rodgers et al 2011; Luescher-Mamashela 2013). The term 'student engagement' has only relatively recently become common currency in the UK, largely subsuming the contested term 'student voice' (Leathwood \& Read 2009). This collective and representational focus has been reinforced with the introduction and subsequent increase in tuition fees over the past decade and a growing sense of 'students as stakeholders' (Kandiko \& Mawer 2013). Student engagement has become enshrined through the quality assurance system, with institutions held accountable to the following expectation: 
Higher education providers take deliberate steps to engage all students, individually and collectively, as partners in the assurance and enhancement of their educational experience (Quality Assurance Agency [QAA], 2012, p.8).

The difference between the pedagogical focus of the US work on engagement, centred around individual student behaviours and institutional environments has been contrasted with the more political motivation behind the UK concentration on representation and realignment of power structures (Buckley 2015b).

UK sector bodies have funded several studies exploring engagement work abroad and its role and relevance in the UK (Little, Locke, Scesa \& Williams 2009; Hardy \& Bryson 2010; Trowler 2010). However, in practice the NSS as a key performance indicator (KPI) continues to drive the decisions of many senior management teams and the institutional development of engagement surveys has been sporadic. The NSS is now used as a diagnostic tool in the process of enhancement (Buckley 2012) but that is largely due to factors unrelated to its suitability for that purpose: it is compulsory for institutions to use, the resources invested in its administration result in a high response rate, and the results have considerable power due to their role in league tables and other public metrics. It was originally designed to provide external audiences (primarily funding organisations and prospective students) with simple information about the quality of provision (HEFCE 2005). It has now taken on an enhancement role officially (Callendar et al 2014) but this is more of an acknowledgement of the overwhelming focus the NSS currently receives within institutions than a validation of its usefulness for enhancement. Institutions are under pressure to improve their scores, and so enhancement processes have been modified to serve the NSS. 
Due to student experience data being publically available and widely used in league tables, student data metrics have become a high-stakes area. Recent government proposals include using student satisfaction, student engagement and learning gain data as part of a new quality assessment framework (Department for Business, Innovation \& Skills [BIS] 2016). Therefore, the development and piloting of engagement surveys in the UK has been done in the context of the NSS and other publically available information.

\section{Development of the UK Engagement Survey (UKES)}

In 2012 a steering group was established to oversee the initial 2013 pilot of the UK Engagement Survey (UKES), formed of academics and professionals from UK universities who were interested in administering engagement surveys at their institutions. This group was coordinated by the UK Higher Education Academy (HEA), a sector body focused on enhancing teaching and learning.

The overarching motivation for the project - aside from institutions' specific aims - was a generalized dissatisfaction with the NSS as a tool for the enhancement of learning and teaching. As described above, the NSS has taken on an enhancement role for which it was not designed. This has been compounded by the fact that many institutions now feel pressured to administer the NSS questionnaire to non-final-year students as an 'early-warning system' (Buckley 2012), losing in the process the institutionally-specific enhancement-focused questions previously used. The UKES initiative was inspired by concerns that this wider use of NSS questions was hindering enhancement efforts, by providing the kind of information useful for simplified public metrics, but not the kind of detail and nuance required for the purposes of evaluating courses and departments, developing interventions and evaluating their impact.

Dissatisfaction with the NSS had led people to look abroad at NSSE and its most prominent international adaptation, AUSSE. NSSE was taken to have three key benefits. Firstly, it provides detail about learning 
and teaching activity. It contains (in its current form) nearly 90 items, the vast majority concerned with core aspects of the learning and teaching process. The core NSS contains currently contains 23 items, only nine of which address central issues in learning, teaching and assessment (though there are also optional items that institutions can choose to use, some of which are focused on learning and teaching). This limits the ability of the NSS to differentiate between courses and to judge the extent to which learning and teaching are reflecting principles of good practice. Secondly, whereas the NSS asks students whether they have received relatively basic elements of a higher education experience, NSSE presents a more ambitious picture focused on more complex aspects of learning and teaching. Thirdly, and relatedly, NSSE reflects a modern focus on learning over teaching by exploring students' participation in learning activities, and the institutional encouragement and support to invest time and effort. The focus of the NSS on students' views of what they have received, rather than the effort they have invested (and how they have been encouraged and supported to invest that effort) was the key factor in leading institutions to look for an alternative.

Early work had already taken place on adapting NSSE for use in the UK at various institutions, including the University of Reading (Creighton et al 2008), the University of Warwick (Taylor et al 2011), the University of Worcester (Scott 2011), Sheffield Hallam University and York St John University (Payne 2012). Many of those behind that early work were represented in the first discussions around UKES.

The key - and sometimes competing - priorities for the design of the UKES questionnaire were: to allow international comparisons; to be appropriate for the UK context; to be short enough to be embedded within standard institutional surveys; and to focus on 'core' academic engagement. The outcome of those discussions was the selection of 14 items focused on four areas: critical thinking; collaborative learning; course challenge; and staff-student interaction (Buckley 2013). Participating institutions agreed to use the 14 items in their own internal surveys and to pass the data to the HEA for aggregation and 
analysis. Institutions mainly ran the UKES survey with non-final-year students, reserving the NSS for final year students to complete. Reflecting the focus on enhancement rather than accountability, institutional results were not made public. Aggregated results were presented in a national report and supplementary benchmarking data were provided to participating institutions.

Following the initial pilot in 2013 , the level of interest was sufficiently high that it was decided to repeat the process in 2014. That in the second year 32 institutions chose to take part demonstrates the appetite in the UK for an alternative to the NSS, designed for enhancement and focused on engagement. In 2015 the first full administration of the survey took place, requiring participating institutions to use a common survey platform and adhere to certain other restrictions designed to improve the reliability of the data. Twenty-four institutions took part in 2015 , fewer than in the previous year, although the number of student responses was similar. NSSE items used in UKES are used under license from Indiana University.

\section{Cognitive Testing}

Taking the UK-based representative notion of student engagement into account, the items for the surveys were extensively cognitively tested with students. Cognitive testing was undertaken for initial pilot in 2013 and the second pilot in 2014. The testing focused on the items being used in the UK (rather than the entire US-based survey), with some minor testing of additional items. The same format was followed for each year of the review. Students were involved in all aspects of the testing: selecting items, creating scales, analysing data and at an institutional level, presenting data.

Cognitive testing for 2013 pilot

The aim for the testing was to include students from a diverse range of institutions, from researchintensive to teaching-intensive institutions, from across the UK. In 2013, 43 students from ten different 
institutions were interviewed. There was a mix of first, second, third, fourth and fifth year students interviewed (due to the nature of the Scottish higher education system and students on longer degree courses such as Medicine), studying a variety of subjects. There was an equal gender representation and participants included European Union (EU), international non-European Union, mature and part-time students.

Individual interviews with students were conducted, following in the tradition of Tourangeau (1984):

1. Comprehension of the question (question intent and meaning of terms)

2. Retrieval from memory of relevant information (recall strategy)

3. Decision processes (motivation and sensitivity/social desirability)

4. Response processes (mapping the response)

The 'think-aloud' method (Willis et al 1999) was used, which directs students to 'think aloud' as they respond to the question, with little interference from the interviewer. This was followed by using verbal prompts, such as "when you answered 'sometimes', how often does that mean?" The research protocol included scripted probes, although spontaneous probes were used as appropriate. Questions were asked with NSSE-based response categories, different versions of expanded response categories, and without specified categories. Scripts and questionnaire versions were updated and tested as interviews progressed.

Four versions of the survey were used mainly to ascertain which types of response categories students would prefer. After the initial set of 14 interviews, the original questionnaire was modified after initial comments from students, and new versions were created. The questionnaires were then re-written and restructured based on the feedback of all interviews conducted up to that point. This aimed mainly at 
simplifying and shortening questions, as well as grouping them differently. This process was conducted

for one further round, resulting in the recommended questions, order of items and response categories.

In addition to adapting new versions of the survey based on students' responses, the data was analysed from all of the interviews at the end of data collection. Following from the work of Conrad \& Blair (1996), we looked at three main stages of students' responses and explored potential problems when analysing the data from the cognitive interviews and focus groups. This included understanding the questions and response options, performing survey tasks and formatting responses.

\section{General findings}

There was great variation in the student experience both in terms of subject-specific characteristics as well as how students related to their own institution. Students were very keen to demonstrate how different their specific degree is from almost all others taught at their university. This was particularly clear when explaining their answers to the different survey questions. Students were perhaps less aware how diverse the student experience can be in other institutions. A couple of students, as is usual in a student survey designed to be administrated across a broad spectrum of subjects, mentioned the fact that the survey was rather general and may perhaps not fully connect with the particularities of each different degree subject:

"One issue I have with this kind of survey is that questions are asked in an abstract way to fit across subjects" (third year, joint honours).

It also emerged that students in different institutions expected different things from their lecturers and tutors. Tentatively, we note that in teaching-intensive institutions students felt closer to their departmental faculty than was the case for students in research-intensive institutions. In the former, there appeared to be more regular interaction between lecturers and students. In many cases, students 
in these institutions appeared to feel more at ease to contact their tutors/lecturers. These trends had an impact on what students expected from their experience and how they subsequently responded to the questions in the survey.

Completing the UKES survey was a formative experience in itself for many students. Students stated that it had made them reflect on their own experiences, and a few noted that this was particularly the case compared to filling out the NSS.

Core items

The grouping of the four items from the Critical Thinking scale was somewhat problematic. Firstly the item root asked students to reflect on the 'coursework', and it was unclear for some students what 'coursework' actually meant. Students found some of the items were either inter-related or that each item was too similar to the others. Also, some responses pointed to the fact that the difference between 'analysing' and 'evaluating' was not clear, particularly for students outside of the social sciences and humanities. After these items had been rephrased in modified versions of the survey, students seemed to have less doubt about what was being asked in each of them. Simpler, more direct and shorter questions appeared to have been preferred by all students, whether they were from the natural sciences or from the humanities. However, it is important to mention that disciplinary differences were noted in students' understanding of these four items.

The Course Challenge scale consisted of three items, one about unpreparedness and two items asking about working hard, and being challenged by coursework. The latter two were the most troublesome questions for students. Some students were not clear what the questions were referring to, or what part of the question to respond to. 
The Collaborative Learning scale was generally interpreted similarly by all interviewees and seemed to be very clear. What appeared to be of relevance was that the practice of formally working with other students in structured activities was extremely rare, whichever degree subject students were doing. However, it was common practice that students at times explained some readings or concepts to other students, as well as having readings or concepts explained to them. These exchanges were very informal, and would mainly occur outside class, at home with flatmates (when they were from the same course), or over coffee and meals.

Students were positive about the Academic Integration scale and thought it was clear and straightforward. Discussing academic performance with staff seemed to be a very rare practice in the majority of institutions. There did not seem to be the opportunity for students to discuss feedback they had received either face-to-face or via email. Students rarely indicated discussion outside of class occurring, particularly in the sciences and engineering, but when students did, it was mainly by email. It was also apparent that around half the students interviewed did not feel comfortable with the idea of initiating contact with a member of the faculty. Students almost never talked about career plans with staff. Students in their first or second year did not appear to see this as important. This question was more relevant for final year students.

\section{Response categories}

Students were least comfortable with open scales and those requiring them to count the number of times they had engaged in something. They were most comfortable and familiar with the non-numeric category scales.

However, what 'sometimes' meant to one student differed from what 'sometimes' meant to other students. Moreover, a student could reply 'often' to one question and 'often' to another and what they meant was considerably different, such as four times a year, or twice a month. What are most important 
are the expectations of regularity and priority when students are surveyed about their experience and their perception of their experience. A student may answer one question with 'sometimes' and by this they mean 'weekly' because they perceive that particular item to be high on their perception of what their student experience should contain. For another item, the same student may reply 'sometimes' meaning they have done the activity once a term. This relates to items students perceive should happen less frequently, such as, for example, discussing career plans or academic performance with staff.

\section{Student feedback}

Unanimously, students were enthusiastic about the idea of engagement questions. Students felt engagement questions showed that the institution valued students' experiences. Therefore, student engagement survey questions seem to be a valid and valued measure of the student experience. Although there was some confusion with the items, students valued the Critical Thinking questions. It was recommended for these questions to be reordered and shortened. In light of disciplinary differences, these should be compared primarily within subject groupings. It was recommended that the Academic Challenge questions should be interpreted with caution, extra emphasis added or deleted. The scales for Academic Integration and Collaborative Learning presented few problematic issues for students.

\section{Cognitive Testing for 2014 Pilot}

The items used in 2013 were used again, modified on the basis of the cognitive testing. In addition, three new groups of items drawn from NSSE were included for institutions to use if they wished, on reflective and integrative learning, the hours students spent on different activities, and students' perceptions of their skills development. Original items were also included on research-led learning and teaching, and students' participation in research and inquiry (Buckley 2014). 
The second pilot was again tested, following the same methodology as in 2013, but with the expanded survey. In 2014, 42 students from eleven different institutions were interviewed. There was a mix of first, second, third, fourth and fifth year students interviewed. About a quarter were first year students, half of the students had just completed their second year of study and the rest were a mix of final year students (comprising third, fourth and fifth year students). The students were drawn from 28 subjects. There was 60/40 female/male gender representation (similar to respondents to the 2013 UK Engagement Survey). Three-quarters of participants were domiciled in the UK, with equal numbers of European Union (EU) and international (non-European Union) students. One in eight students lived in university accommodation, another eighth lived in their own home and the rest lived in rental accommodation. Half of the sample was in the 19-21 age range; another quarter was 22-24; and the rest ranged from 25-42. The sample included a number of mature students and five students studying via distance.

Three versions of the survey were used mainly to test wording, benchmarks and scales of questions. After the first set of 9 interviews, the original questionnaire was modified after initial comments from students, and a new version was created. This was tested during a further set of 21 interviews. The questionnaire was then re-written and restructured based on the feedback of all interviews conducted up to that point. This aimed mainly at focusing the wording of the questions, as well as testing additional questions. This process was conducted for one further round of 11 interviews.

Core items

The items carried over from the 2013 pilot remained stable. The disciplinary differences noted for the Critical Thinking scale (now called Higher Order Learning) remained. For the two new scales on researchled teaching and engagement in research, students were split about referring to engagement with their own research (such as writing essays or a dissertation) or with research generally (such as that 
conducted by their lecturers). A majority of students felt more comfortable answering the first set of items (exploring the extent to which existing research findings and methods have been incorporated into curricula) than the second (focusing on students' own research activities). The few students who preferred the second scale tended to be social sciences/humanities students from research-intensive universities. The most problematic element with the second scale was the "open-ended lines of enquiry" part of the question, which many students failed to comprehend and many had to read several times. The two scales on research and inquiry were merged into one four-item scale for the final version.

Regarding the Time Spent scale, students noted challenges with the accuracy of their responses, although they said it was generally a close approximation. Students commented that of all the questions in the survey, those in the Time Spent scale made them reflect the most on their experience, and how they prioritised their time. Many students commented that filling out this scale made them think they should spend more time on academic work. The Skills Development scale worked well. A few students noted that the first six items were core activities of university study, and that the rest were also important, but less central than the former set.

\section{Findings}

Full results, and statistical analyses relating to the validity and reliability of the questionnaire, are available in full in the first three annual reports published (Buckley 2013, 2014, 2015a). Here we summarise the findings relating to 'construct validity' - the extent to which the questionnaire measures the different aspects of engagement that it purports to measure - as well as new findings relating to disciplinary differences.

Construct validity 
One of the historical concerns about NSSE and its derivatives has been that results are reported using 'benchmarks' - averaged scores for groups of items - that have limited empirical support (Porter 2011). NSSE staff have stated in response that these benchmarks were not intended to represent "unitary constructs", but to have "have clear face validity and actionable import for institutional users" (McCormick et al 2013b). Nevertheless when the questionnaire was revised in 2013 new 'indicators' were created to replace the benchmarks, which did better reflect the empirical structure of the instrument (McCormick et al 2013a). With an eye on these methodological concerns, construct validity has been a focus of the development of UKES from the outset.

Over the three years of developing the UKES survey, factor analysis has revealed good construct validity, and that the conceptual structure was broadly as intended. Statistical discrepancies noted in the analysis of the pilot year quantitative data from 2013 and 2014 were explained by analysis of the cognitive testing data. The iterative process of developing the survey has enabled both strong construct validity and strong face validity in the constructs.

The only persistent issue has been a difficulty in reliably capturing students' perceptions of the challenge of their course. In the first administration, the three items intended to address course challenge included a negatively-worded item, which appeared to seriously limit the internal coherence of the scale. This item was phrased positively for the second administration in 2014 , but removed in 2015 . In 2015, the two items intended to explore course challenge were found to constitute part of a different scale, along with four questions on critical thinking.

\section{Disciplinary differences}

The impact of discipline of study on students' survey responses is well-documented, including for both the NSS (Marsh \& Cheng 2008; Surridge 2009; HEFCE 2014) and NSSE and its derivatives (Nelson Laird et al 2008; NSSE 2010; Pike et al 2012; Leach 2016). The differing teaching environments and practices, as 
well as varying values and norms, have a powerful impact. Pronounced disciplinary differences are similarly seen in UKES. As an extreme example, in the 2013 survey it was found that while overall less than $10 \%$ of students felt that there was 'very little' emphasis in their course on the evaluation of a point of view, decision, or information source, that figure for students in maths and computer sciences was $40 \%$ (Buckley 2013). This kind of dramatic difference by discipline underlines the importance of comparing results within disciplines and across institutions in order to gain insight.

To further explore the relationship between disciplinary norms and cultures and engagement, data from the 2015 UKES were analysed using categories developed by Biglan (1973) and since applied in a range of research (see for example Neumann et al 2002 and Lindblom-Ylänne et al 2006). This categorisation uses two axes: hard-soft, which relates to the existence of more dominant paradigms within disciplines, and greater consensus about methods and content; and pure-applied, which relates to the level of concern with practical problems. The 49 subjects used at level 2 of the Joint Academic Coding System (JACS) - with the exception of the 'Combined' category - were each categorised as hard or soft, and pure or applied, following Nelson Laird et al (2008).

The UKES data are drawn from the 2015 administration, which involved 24 institutions and in which 24,387 students participated. Not all students were invited to respond to all scales, as some were optional for institutions to use if they wished. The number of institutions participating in each scale, and the number of student responses, are shown in Table 1. Data were used from six UKES scales that explicitly address student engagement; the additional scales on perception of skills development, and on the time spent on a range of life activities were not used. The overall response rate to the survey was $17 \%$, broadly in line with the 2013 and 2014 surveys.

$<$ Table 1 here $>$ 
One-way analysis of variance (ANOVA) was used to ascertain whether there were significant differences between the UKES scales for the two Biglan axes. ANOVA is a method for exploring differences between mean values for sub-groups, in this case different subject groups. ANOVA compares the variance between the groups with the variance within each of the groups, in order to establish whether the difference between the groups is greater than would be expected to be caused by chance. The differences in mean values and the $p$-values for those differences are shown below. Where a $p$-value is equal to or less than 0.01 , there is at least a $99 \%$ probability that the difference is not due to chance. Table 2 shows the values for the hard-soft axis. Positive values for the differences in mean values show that the value for the 'soft' discipline group was higher than for the 'hard' discipline group; negative values indicate the reverse. A difference of 1 would correspond to the soft discipline group averaging one whole response option higher than the hard discipline group (e.g. 'often' rather than 'sometimes').

$<$ Table 2 here $>$

Table 2 shows there were statistically significant differences (at the 0.01 level) between the 'hard' and 'soft' groups for all of the scales except Staff-Student Partnership. For all of those scales, except Collaborative Learning, students in the 'soft' group reported higher levels of engagement than those in the 'hard' group. The largest difference is for the Reflective and Integrative Learning scale, where students in the 'soft' discipline group report a score around one-fifth of a response option higher than those in the 'hard' discipline group.

Previous work in the US by Nelson Laird et al (2008) has found similar results to those reported here. They found that the 'soft' group scored higher for Critical Thinking and for Reflective and Integrative Learning - mirroring our results - and attributed it to the lack of a dominant paradigm in those subjects: 'Students' majoring in fields with less consensus about content and methods of inquiry (soft fields) tend 
to use deep approaches to learning to a greater degree than those majoring in fields with greater consensus (hard fields)" (Nelson Laird et al 2008, p.489).

$<$ Table 3 here $>$

Table 3 shows the differences between the 'pure' and 'applied' groups. Positive values indicate that the value for the 'applied' group was higher than that for the 'pure' group. Table 3 shows that there were fewer statistically significant differences between the pure and applied groups than between the hard and soft groups. Only three of the six scales - Collaborative Learning, Reflective and Integrative Learning, and Staff-Student Partnership - showed significant differences on the pure-applied axis, and all of them were in favour of the 'applied' group. Of the differences, by far the largest is for Collaborative Learning where the mean for the 'applied' group is over one-fifth of a response option higher than for the 'pure' group.

To supplement these tables, Figure 1 shows the values for the four discipline clusters generated by the two axes: hard pure (e.g. biology); hard applied (e.g. engineering); soft pure (e.g. philosophy); soft applied (e.g. social work). The bars represent the mean values for the six scales.

<Figure 1 here>

In line with Table 2, Figure 1 shows a difference for Critical Thinking and Engagement with Research and Inquiry between hard pure and hard applied on one hand, and soft pure and soft applied on the other. However the pronounced difference seen in Table 2 for Reflective and Integrative Learning, is seen in Figure 1 as largely related to the markedly low score for the hard pure group of subjects. The finding from Table 3 of a clear difference between the pure and applied groups for Collaborative Learning is also seen in Figure 1. That scale is the only scale for which any substantial difference exists between the soft 
applied and soft pure groups; those groups have a much more similar engagement profile than the hard applied and hard pure groups.

\section{Conclusion}

Previous work has found marked differences across fields of study for UKES results, raising issues about broad national comparisons at the institution level, particularly where institutions have very different subject portfolios. The analysis reported here reveals subject differences at a more coarse grain: students in soft subjects report higher levels of engagement around critical thinking and reflective and integrative learning, while those in applied subjects feel they collaborate more with other students. Hard pure subjects such as physics and biology have the most distinctive patterns of engagement.

The emergence of UKES indicates both the dissatisfaction with the NSS as a tool for enhancement, and the growing awareness of the importance of student engagement for understanding students' course experiences. There are plans to broaden the scope of the NSS to include engagement, but the primary focus of that survey will remain satisfaction. UKES constitutes the successful UK adaptation and implementation of the pre-eminent international instrument for exploring students' academic engagement.

\section{Acknowledgement}

This research was funded in part through grants from the Higher Education Academy. The HEA also granted permission to publish the results of analysis using the individual-level UKES dataset. The HEA makes aggregated data publicly available on their website: www.heacademy.ac.uk 


\section{References}

Astin, A. (1984). Student involvement: A developmental theory for higher education. Journal of College Student Development 25(4): 297-308

Biglan, J. (1973). The characteristics of subject matter in different academic areas. Journal of Applied Psychology 57(3): 195-203Browne, J. (2010) Securing a Sustainable Future for Higher Education: An independent review of higher education funding and student finance. Report. (Available from

http://www.bis.gov.uk/assets/biscore/corporate/docs/s/101208securingsustainablehighereducationbro wnereport.pdf.)

Buckley, A. (2012) Making it Count: Reflecting on the National Student Survey in the process of enhancement. York: Higher Education Academy. Available at:

https://www.heacademy.ac.uk/system/files/resources/making it count.pdf

Buckley, A. (2013) Engagement for Enhancement: Report of a UK survey pilot. York: Higher Education Academy. Available at:

https://www.heacademy.ac.uk/system/files/engagement for enhancement final 0.pdf

Buckley, A. (2014) UK Engagement Survey: The second pilot year. York: Higher Education Academy. Available at: https://www.heacademy.ac.uk/system/files/resources/ukes report 2014 v2.pdf

Buckley, A. (2015a) Students' Perceptions of Skills Development. York: Higher Education Academy. https://www.heacademy.ac.uk/system/files/ukes 2015.pdf

Buckley, A. (2015b) How radical is student engagement? (And what is it for?). Student Engagement and Experience Journal 3(2). 
Callendar, C., Ramsden, P. \& Griggs, J. (2014). Review of the National Student Survey. Bristol: HEFCE.

Available at:

http://www.hefce.ac.uk/media/hefce/content/pubs/indirreports/2014/Review,of,the,NSS/2014 nssrevi

$\underline{\text { ew.pdf }}$

Chickering, A. W., \& Gamson, Z. F. (1987). Seven principles for good practice in undergraduate education. AAHE Bulletin, 39(7), 3-7.

Coates, H. (2010). Development of the Australasian Survey of Student Engagement (AUSSE).Higher Education, 60: 1-17.

Coates, H. \& McCormick, A. (Eds.) (2014). Engaging University Students: International insights from system-wide studies. London: Springer.

Conrad, F., \& Blair, J. (1996, August). From impressions to data: Increasing the objectivity of cognitive interviews. In Proceedings of the Section on Survey Research Methods, Annual Meetings of the American Statistical Association (pp. 1-10).Creighton, J., Beasley, S. \& Jeffreys, P. (2008). Reading Student Survey 2008. Reading: University of Reading.

Department for Business Innovation and Skills (2011). Higher Education: Students at the Heart of the System. (Cm 8122). London: DBIS. Available at: http://www.bis.gov.uk/assets/biscore/highereducation/docs/h/11-944-higher-education-students-at-heart-of-system.pdf

Department for Business, Innovation and Skills (2016). Fulfilling Our Potential: Teaching excellence, social mobility and student choice. (Cm 9141). London: DBIS. Available at:

https://www.gov.uk/government/uploads/system/uploads/attachment data/file/474227/BIS-15-623$\underline{\text { fulfilling-our-potential-teaching-excellence-social-mobility-and-student-choice.pdf }}$ 
Entwistle, N., Hanley, M. \& Hounsell, D. (1979). Identifying distinctive approaches to studying. Higher Education 8(4): 365-380

Hanbury, A. (2007). Comparative Review of National Surveys of Undergraduate Students. The Higher Education Academy. Available at:

http://www.heacademy.ac.uk/resources/detail/ourwork/nss/NSS comparative review resource

Hardy, C. and Bryson, C. (2010). Student Engagement: Paradigm change or political expediency?

Brighton: Art, Design and Media Subject Centre. Available at:

http://www.adm.heacademy.ac.uk/resources/features/student-engagement-paradigm-change-orpolitical-expediency/

Harvey, L. (2003). Scrap that student survey now. Times Higher Educational Supplement (THES), 12

December. Available at: $\underline{w w w . t h e s . c o . u k / s e a r c h / s t o r y . a s p x ? s t o r y ~ i d=2008131}$

HEFCE (2005). National Student Survey 2005: Outcomes of consultation and guidance on next steps.

Bristol: HEFCE. Available at: http://dera.ioe.ac.uk/4972/1/04 33.pdf

HEFCE (2014). Findings and Trends From the National Student Survey. Bristol: HEFCE. Available at:

http://www.hefce.ac.uk/media/hefce/content/pubs/2014/201413/HEFCE2014 13\%20-

\%20corrected\%2012\%20December\%202014.pdf

HEFCE (2015). Review of Information About Learning and Teaching, and the Student Experience:

Consultation on changes to the National Student Survey, Unistats and information provided by

institutions. Bristol: Higher Education Funding Council for England. Available at:

http://www.hefce.ac.uk/media/HEFCE,2014/Content/Pubs/2015/201524/HEFCE2015 24.pdf Gibbs, G. (2010). Dimensions of Quality. York: HEA. Available at: 
http://www.heacademy.ac.uk/assets/documents/evidence informed practice/Dimensions of Quality. pdf

Gibbs, G. (2012). Implications of 'Dimensions of Quality' in a Market Environment. York: HEA. Available at:

http://www.heacademy.ac.uk/assets/documents/evidence informed practice/HEA Dimensions of Qu ality 2.pdf

Kandiko, C. B. \& Mawer, M. (2013). Student Expectations and Perceptions of Higher Education. London: King's Learning Institute. Available at: https://www.kcl.ac.uk/study/learningteaching/kli/People/Research/DL/QAAReport.pdf

Kuh, G. D. (2001a). The National Survey of Student Engagement: Conceptual framework and overview of psychometric properties. Bloomington: Indiana University Center for Postsecondary Research.

Kuh, G. D. (2001b). Assessing what really matters to student learning: Inside the National Survey of Student Engagement. Change, 33(3), 10-17, 66.

Kuh, G. D. (2009). The National Survey of Student Engagement: Conceptual and empirical foundations. New Directions for Institutional Research (141): 5-20.Leach, L. (2016). Exploring discipline differences in student engagement in one institution. Higher Education Research \& Development 35(4): 772-786.

Leathwood, C., and B. Read. 2009. Gender and the Changing Face of Higher Education. Buckingham: Open University Press and SRHE.

Lindblom-Ylänne, S., Trigwell, K., Nevgi, A. \& Paul Ashwin (2006). How approaches to teaching are affected by discipline and teaching context. Studies in Higher Education 31(3): 285-298. 
Little, B., Locke, W., Scesa, A. \& Williams, R. (2009). Report to HEFCE on Student Engagement. HEFCE, Bristol, UK. Available at:

https://www.hefce.ac.uk/media/hefce/content/pubs/2009/rd0309/rd03 09.pdf

Luescher-Mamashela, T. (2013). Student representation in university decision-making: Good reasons, a new lens? Studies in Higher Education 38 (10): 1442-1456

Marsh, H. \& Cheng, J. (2008). National Student Survey of Teaching in UK Universities: Dimensionality, multilevel structure, and differentiation at the level of university and discipline - preliminary results. York: Higher Education Academy. Available at: https://www.heacademy.ac.uk/system/files/national student survey of teaching in uk universities dimensionality multilevel structure and differentiation at the level of university and discipline pr eliminary results.pdfMarton, F. and Säljö, R. (1976). On qualitative differences in learning - 1: Outcome and process. British Journal of Educational Psychology 46: 4-11.

McCormick, A., Gonyea, R. \& Kinzie, J. (2013a). Refreshing engagement: NSSE at 13. Change: The Magazine of Higher Learning (45)3: 6-15.

McCormick, A., Kinzie, J. \& Gonyea, R. (2013b). Student engagement: Bridging research and practice to improve the quality of undergraduate education. Higher Education: Handbook of theory and practice 28: 47-92.

Nelson Laird, T., Shoup, R., Kuh, G. \& Schwarz, M. (2008). The effects of discipline on deep approaches to student learning and college outcomes. Research in Higher Education 49: 469-494.

Neumann, R., Parry, S. \& Becher, T. (2002). Teaching and learning in their disciplinary contexts: A conceptual analysis. Studies in Higher Education 27(4): 405-417. 
NSSE (2010). A Guide to Contextualising your NSSE Data: Cognitive Interviews and Focus Groups. Available at: http://nsse.iub.edu/pdf/Cognitive interviews facilitation guide.pdf

Ouimet, J., Carini, R., Kuh, G. \& Bunnage, J. (2001). Using Focus Groups to Establish the Validity and Reliability of a College Student Survey. Presented at the 2001 Association of Institutional Research Forum, Long Beach, CA - June 4, 2001.

Pace, R. (1982). Achievement and the Quality of Student Effort (Department of Education, Washington DC).

Pace, C. (1984). Measuring the Quality of College Student Experiences (University of California, Los Angeles).

Pascarella, E. T. \& Terenzini, P. T. (2005). How College Affects Students: A third decade of research. San Francisco: Jossey-Bass.

Payne, A. (2012). How satisfied and engaged are our students? Yorktalk 14(Winter).

Pike, G., Smart, J. \& Ethington, C. (2012). The mediating effects of student engagement. Research in Higher Education 53: 550-575.

Porter, S. (2011). Do college student surveys have any validity? The Review of Higher Education 35(1): 45-76.

QAA (2012). Quality Code, Chapter B5. Gloucester: QAA. Available at:

http://www.qaa.ac.uk/en/Publications/Pages/Quality-Code-Chapter-B5.aspx\#.Vsol3vCXQng

Ramsden, P. (1991). A performance indicator of teaching quality in higher education: The Course Experience Questionnaire. Studies in Higher Education, 16(2): 129-150. 
Rodgers, T., Freeman, R. , Williams, J. and Kane, D. (2011). Students and the governance of higher education: A UK perspective. Tertiary Education and Management 17 (3): 247-260.

Sabri, D. (2011). What we miss when we focus on the student experience. Discourse: Cultural Politics of Education, 32(5): 657-667

Scott, I. (2011). Survey of Student Activity and Engagement. York: Higher Education Academy.

Surridge, P. (2009). The National Student Survey Three Years On: What have we learned? York: Higher Education Academy. Available at:

https://www.heacademy.ac.uk/system/files/nss three years on surridge 02.06.09.pdf

Taylor, P., Koskela, J. \& Lee, G. (2011). Shaping History. York: Higher Education Academy

Tourangeau, R. (1984). Cognitive sciences and survey methods. In T. Jabine, M. Straf, J. Tanur, \& R.

Tourangeau (Eds.), Cognitive Aspects of Survey Methodology: Building a Bridge Between Disciplines, pp.

73-100. Washington, DC: National Academy Press.

Trowler, V. (2010). Student Engagement Literature Review. York: Higher Education Academy. Available at: https://www.heacademy.ac.uk/system/files/studentengagementliteraturereview 1.pdf WiersJenssen, J., Stensaker, B. \& Grøgaard, J. B. (2002). Student satisfaction: towards an empirical deconstruction of the concept, Quality in Higher Education, 8, 183-195.

Williams, J. \& Cappuccini-Ansfield, G. (2007). Fitness for purpose? National and institutional approaches to publicising the student voice. Quality in Higher Education, 13: 2, 159- 172.

Willis, G., DeMaio, T., \& Harris-Kojetin, B. (1999). Is the bandwagon headed to the methodological promised land? Evaluation of the validity of cognitive interviewing techniques. In M. Sirken, D. 
Herrmann, S. Schechter, N. Schwarz, J. Tanur, \& R. Tourangeau (Eds.), Cognition and Survey Research. New York: Wiley. 
Table 1: Number of institutions and students contributing to UKES scales

\begin{tabular}{|l|r|r|}
\hline Scale & Number of participating & \\
\hline Critical thinking scale & institutions & 24 \\
\hline Collaborative learning & 24 & 24367 \\
\hline Staff-student interaction & 24 & 24370 \\
\hline Reflective and integrative learning & 24 & 24361 \\
\hline Engagement with research and inquiry & 17 & 19455 \\
\hline Staff-student partnership & 20 & 20371 \\
\hline
\end{tabular}


Table 2: Differences between scales for the hard-soft axis

\begin{tabular}{|l|r|r|}
\hline Scale & Difference in mean & \multicolumn{2}{l|}{ Significance } \\
\hline Critical thinking scale & 0.15 & 0.00 \\
\hline Collaborative learning & -0.08 & 0.00 \\
\hline Staff-student interaction & 0.15 & 0.00 \\
\hline Reflective and integrative learning & 0.20 & 0.00 \\
\hline Engagement with research and inquiry & 0.19 & 0.00 \\
\hline Staff-student partnership & & 0.01 \\
\end{tabular}


Table 3: Differences between scales for the pure-applied axis

\begin{tabular}{|l|r|r|}
\hline Scale & Difference in mean & \multicolumn{1}{|l|}{ Significance } \\
\hline Critical thinking scale & -0.02 & 0.08 \\
\hline Collaborative learning & 0.21 & 0.00 \\
\hline Staff-student interaction & 0.01 & 0.13 \\
\hline Reflective and integrative learning & & 0.08 \\
\hline Engagement with research and inquiry & -0.01 & 0.20 \\
\hline Staff-student partnership & & 0.05 \\
& & \\
\hline
\end{tabular}


Figure 1: Scale means for four Biglan discipline groups

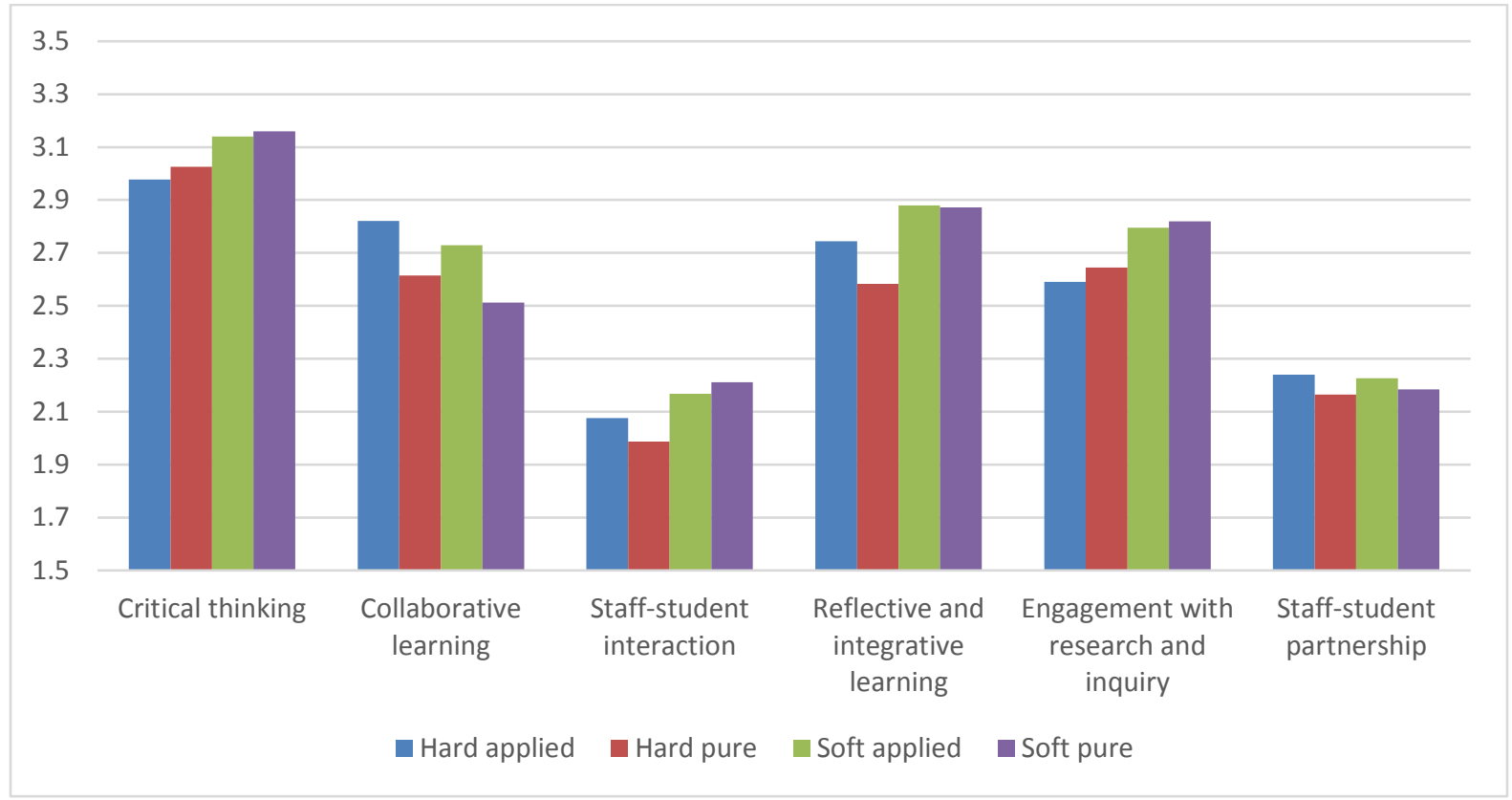

